\title{
A brief review of the effects of age on second language acquisition: Is younger better?
}

\author{
Elise, Yi Wu \\ The University of Oxford, Oxford, United Kingdom
}

Received: November 7, 2021 / Accepted: January 2, 2022 / Published Online: January 29, 2022

(C) Pioneer Publications LTD 2022

\begin{abstract}
The present review provides a brief overview of relevant theories and empirical findings relating to the effects of age on second language acquisition and evaluates the notion of 'younger is better' in educational language learning contexts. While some evidence suggests that age is a strong predictor of language learning, there are certain caveats required. The implications of research into the effects of age on second language acquisition for language teaching are also explored.
\end{abstract}

Keywords second language acquisition; age; critical period; learning context

\section{Introduction}

The study of the effects of age on second or additional language (L2) learning has attracted the interest of numerous researchers over many decades. Birdsong and Vanhove (2016) observed that learning of a second language in infancy is generally associated with effortless language processing, fluent speech, and the development of an accent that is indistinguishable from that of native speakers of that language. On the other hand, learners who learn their second language later in life tend to perform significantly more poorly than native speakers of the language on measurements of lexical knowledge, grammatical knowledge and processing speed, and speak the second language with a discernible non-native accent.

While researchers generally agree that there exists a relationship between age and success in second language learning, where younger learners typically achieve greater success in learning a second language over time as compared to a learner who begins learning the L2 only in adulthood, the precise nature of this relationship is still hotly debated, with numerous explanations put forward in an attempt to explain this phenomenon. This article will discuss the effects of age on second language acquisition and will evaluate the veracity of the notion of 'younger is better' in educational language learning contexts. It will then explore implications of research related to age effects on second language acquisition on language teaching.

\section{Discussion of the effect of age on SLA}

\subsection{Relevant theories and empirical studies on the effects of age on SLA}

Some researchers have suggested that the relationship between age and success in second language acquisition is due to the existence of a critical period in language exposure and learning. The critical period perspective in language learning suggests that after a certain maturational point, the L2 learner is no longer capable of achieving native-like proficiency in the language (Long, 1990). The critical period perspective on second language acquisition also appears to be supported by studies on immigrants who had arrived in a new country that used a different native language. Oyama (1976) found that amongst immigrants who had learned English at various ages and had been in the United States for various amounts of time, age at arrival was a strong predictor of degree of accent, while the length of stay had very little effect.

Other practice and motivational factors were related to participants' accents only by virtue of their correlation with age at arrival, suggesting that a sensitive 
period exists for the acquisition of a non-native phonological system. Similarly, Patkowski (1980) tested the syntactic proficiency in English of sixty-seven immigrants who had come to the United States at various ages and resided in this country for various periods of time. These participants were also administered a questionnaire to gather information concerning practice and instructional variables. Patkowski (1980) found that the participants' age at arrival was a strong predictor of syntactic proficiency while other independent variables had very little effect, providing support for the hypothesis of an age-related limitation on the ability to acquire full command of syntax in a second language.

However, the relationship between age and second language acquisition is not necessarily clear-cut. For instance, in research evaluating the results of second language programs conducted during primary and elementary school, researchers generally found that students who were given early exposure to a second language and were then integrated into classes containing students without such experience did not maintain a clear advantage in L2 proficiency for more than a short period of time over those who began learning the L2 language at secondary school (e.g., Oller \& Nagato, 1974). In a similar vein, some studies also seemed to demonstrate an advantage for younger learners (e.g., Cochrane \& Sachs, 1979), while others seemed to indicate that older children and adults were better at second language learning than younger children (e.g., Asher \& Price, 1967; Olson \& Samuels, 1973). Krashen et al. (1979) attempted to resolve these inconsistencies by categorizing the research studies investigating this topic into two types of empirical studies - namely studies looking at the effect of age and initial rate of learning of the second language, and studies looking at the effect of age on eventual attainment of the second language. After the studies were categorized as such, Krashen et al. (1979) were able to make certain generalizations to account for the supposed inconsistencies between the different studies that helped provide clarity on the effect of age on second language acquisition. Krashen et al. (1979) observed that, in naturalistic settings, older learners were able to acquire certain aspects of a second language at a faster rate than younger learners during the beginning of the language acquisition process, such as in areas such as morphological and syntactic development in the second language. However, in naturalistic settings, the younger learners tended to catch up and eventually surpass older children and adults in their eventual proficiency in the second language. Consistent with Krashen et al. (1979)'s observations, Munoz and Singleton (2011) also observed that comparisons made between the age of acquisition of the second language and the length of residence in the target language community revealed that the correlation between age of initial learning and proficiency is higher than the correlation between the duration of residence and proficiency, providing further support for the impact of age effects on second language acquisition.

\subsection{Evaluation of the notion of 'younger is better' in educational language learning contexts}

Research studies suggest that the idea of 'younger is better' in educational language learning contexts requires certain caveats. Firstly, the idea of 'younger is better' may be more applicable to learners learning the L2 in more naturalistic settings, as compared to learners learning the L2 in more formal settings, such as in the second language classroom. Munoz (2008) found that early-starting formal L2 learners did not surpass latestarting formal L2 learners in varied measures of L2 proficiency even in the long term. Similarly, Munoz (2006) tested Spanish-Catalan college students with an average of more than ten years of instruction in their L2 (English language) and found that age did not correlate significantly with participants' performance on general proficiency, lexical knowledge, and phonetic perception. As these studies were carried out within a formal school context, Munoz and Singleton (2011) suggested that learners learning the L2 in such contexts received limited amounts of language input, rarely exceeding seven hundred hours, and that the limited quantity of input that learners in a formal second language learning setting meant that younger learners would require a much longer period of time to reach the same level or outperform older learners. This was because older learners would have higher cognitive maturity and would be better able to use strategies to support their learning and acquisition of the L2 (Tragant \& Victori, 2006; Victori \& Tragant, 2003).

Secondly, the idea of 'younger is better' in educational language learning contexts is also confounded to some extent by contextual variables such as the extent of contact the learner has with the L2, as well as the quality of L2 input received by the learner, which in turn affects the relationship between age and eventual proficiency in the second language. The quality of L2 input received by the learners and the amount of contact with the L2 during second language acquisition also impact their rates of acquisition of the language as well as the ultimate level of proficiency that they achieve, with a higher quality of L2 input and higher amount of contact with the L2 leading to better L2 proficiency outcomes. For instance, Flege et al. (1995) observed that L2 learners' extent of engagement in informal personal domains with others in the L2 was a useful predictor of native-like pronunciation, while MarinovaTodd (2003) found that the most proficient L2 speakers lived with native speakers. Young learners and older learners differ greatly in sociocultural context, making it difficult to untangle the contribution of context from that of age in second language proficiency and attainment. Specifically, earlier exposure to the L2 may allow 
the younger learner to be exposed to a greater variety of formal and informal contact sources within both professional and personal domains with greater frequency and consistency of personal contact. This results in more practice opportunities and increased fluency and proficiency in the L2. For example, Jia and Aaronson's (2003) longitudinal study found that the five-year-old in their study had more opportunities to interact with others in their L2, and had more L2 speaking friends as compared to adolescents participating in the same study. Similarly, in a study involving adult participants from different countries, Jia et al. (2002) found that participants' performance in an oral and written grammaticality judgment test in their L1 and in English (participants' L2) were negatively correlated, and that adult participants with greater proficiency in their L2 reported using the L2 at home more than participants who demonstrated a lower proficiency in their L2. As such, it is unclear if the higher final proficiency in the L2 achieved by younger learners is due to solely their age of exposure to the L2, or due to confounding factors such as differences in the number of interactions involving the L2, differences in the relative use of the L1 relative to the L2, and differences in the quality of L2 input received from their interactions.

Thirdly, the idea of 'younger is better' in educational language learning contexts is also confounded to some extent by the influence of psychological and socio-affective factors. Moyer (2004) found that psychological factors, such as one's satisfaction with their own phonological attainment in the L2 and personal motivation to be fluent in the L2 were reliably able to predict about $74 \%$ of the variance in proficiency between L2 German learners. The predictive power of these two variables was observed to be greater than the effect of age of acquisition and length of residence in Germany combined (which only accounted for $56 \%$ of the total variance in proficiency between L2 German learners), indicating that psychological factors also played a significant and influential role in the eventual L2 proficiency of the learner. Learners with greater motivation and intention to be fluent in the L2 and who were satisfied with their own phonological attainment in the L2 were more likely to achieve higher proficiency and fluency in their L2. In a similar vein, the learner's linguistic and cultural affiliation to the L2 also impacts their eventual L2 proficiency and fluency - L2 learners who are more motivated to sound like a native speaker are more likely to achieve higher fluency and proficiency in their L2.

On the other hand, learners who consciously or unconsciously decide to develop their L2 only to a certain extent for functionality purposes, allowing them to be fluent, but without having to adopt new ways at the perceived expense of their old, familiar ways (Pavlenko \& Lantolf, 2000) would tend to have more variations in their speech as compared to native L2 speakers. This indicates that psychological and socio-affective factors, whose effects may be more pronounced in second language acquisition in older learners, may also impact the relationship between age and second language proficiency. Younger learners are typically exposed to L2 due to reasons beyond their control, such as due to family migration to another country, and may not have specific motivations in relation to learning the L2. On the other hand, psychological and affective factors are more likely to play a more impactful role on their motivation to learn the L2, in turn influencing factors such as their willingness to engage with the L2 in different contexts, the amount of practice they have with the L2, and their overall proficiency and fluency in the L2.

\subsection{Implications on Language Teaching}

The factors that affect the relationship between age and second language acquisition have implications for language teaching. Regardless of the age of the learner, it highlights the importance of ensuring that the learner is able to gain more exposure to higher quality input in the L2 through interacting with others in the language. This suggests that language teaching should try to incorporate as many naturalistic immersion opportunities as possible for learners to practice their L2, and to be exposed to quality input in the L2. This can include opportunities to interact with one another, with fellow L2 learners who are at a higher proficiency in the L2, as well as native users of the L2. Webb (2020) proposed that language learning in L2 should incorporate extensive exposure to the $\mathrm{L} 2$ through the provision of multiple types of meaning-focused input based on the learners' interest alongside an extensive reading of L2 texts on topics that the learner is interested in, such as viewing of L2 television shows and videos as well as listening to L2 songs. Having multiple modes of input incorporated within a language learning program would increase the possibility that learners will find a source of input that particularly motivates them to learn the L2 on their own, hence increasing their extent of exposure to the $\mathrm{L} 2$.

It also highlights the importance of considering psycho-social and affective factors, such as the interest, learning needs, and the background knowledge of the learner when language teachers select L2 learning materials and resources for learners. Doing so will help increase the motivation of learners towards the L2, in turn motivating them to want to engage with and interact more using the L2. This is aligned with Laufer and Hulstijn (2001)'s involvement load hypothesis, which suggests that both cognitive and motivational components are involved during human learning. In this instance, learners who are more intrinsically interested in the L2 input that they receive would allocate more attention to the input and processing information encountered within the input to a higher degree, leading to higher retention rates of the L2 input they encountered. 
Over time, such incremental, incidental learning of the L2 while being engaged in meaning-focused tasks will enable the learner to gain a higher proficiency and fluency in their L2 gradually.

\section{Conclusion}

In conclusion, age effects on second language acquisition are influenced by varied environmental, contextual, and individual factors, and hence the idea of 'younger is better' in educational language contexts does not apply all the time. In the area of language teaching, language teachers can use the knowledge of the influence of environmental, contextual, and individual-based factors to shape the L2 learning environment within their classroom, as well as provide recommendations to help learners shape their L2 learning environment outside the language classroom. Doing so would help learners achieve greater proficiency and fluency in their L2 compared to the status quo, regardless of their age.

Elise Yi Wu is pursuing her MSc in Applied Linguistics for Language Teaching at The University of Oxford. She holds a BSc in Psychology and MSc in Research Methods in Psychology from University College of London. Elise has gained 11 years of teaching experience in both the UK and China and taught English to adults in various academic settings. Moreover, Elise is the exclusive strategic partner for British English teaching with Youdao, one of China's largest online learning platforms, with over one hundred million users. Her research interests include attainment of L2 pronunciation of English by adult learners, mobileassisted language, and learning strategies.

\section{References}

Asher, J. J., \& Price, B. S. (1967). The learning strategy of the total physical response: Some age differences. Child Development, 1219-1227. https://doi.org/10.2307/1127119

Birdsong, D., \& Vanhove, J. (2016). 9 Age of SecondLanguage Acquisition: Critical Periods and Social Concerns. Bilingualism Across the Lifespan: Factors Moderating Language Proficiency. https://doi.org/10.1037/14939-010

McCrae Cochrane, R., \& Sachs, J. (1979). Phonological learning by children and adults in a laboratory setting. Language and Speech, 22(2), 145-149. https://doi.org/10.1177/002383097902200204

Flege, J. E., Munro, M. J., \& MacKay, I. R. (1995). Factors affecting strength of perceived foreign accent in a second language. The Journal of the Acoustical Society of America, 97(5), 3125-3134. https://doi.org/10.1121/1.413041
Jia, G., D. Aaronson \& Y. Wu (2002). Long-term language attainment of bilingual immigrants: Predictive variables and language group differences. Applied Psycholinguistics 23(4), 599-621. https://doi.org/10.1017/S0142716402004058

Jia, G., \& D. Aaronson (2003). A longitudinal study of Chinese children and adolescents learning English in the United States. Applied Psycholinguistics 24, 131-161. https://doi.org/10.1017/S0142716403000079

Krashen, S. D., Long, M. A., \& Scarcella, R. C. (1979). Age, rate and eventual attainment in second language acquisition. TESOL quarterly, 573582. https://doi.org/10.2307/3586451

Laufer, B., \& Hulstijn, J. (2001). Incidental vocabulary acquisition in a second language: The construct of task-induced involvement. Applied Linguistics, 22(1), 1-26. https://doi.org/10.1093/applin/22.1.1

Long, M. H. (1990). Maturational constraints on language development. Studies in second language acquisition, 12(3), 251-285.

https://doi.org/10.1017/S0272263100009165

Todd, S. (2003). 3. Know Your Grammar: What the Knowledge of Syntax and Morphology in an L2 Reveals about the Critical Period for Second/foreign Language Acquisition. In M. García Mayo \& M. García Lecumberri (Ed.), Age and the Acquisition of English as a Foreign Language (pp. 59-74). Multilingual Matters.

https://doi.org/10.21832/9781853596407-004

Moyer, A. (2004). Age, accent and experience in second language acquisition. An integrated approach to critical period inquiry. Clevedon: Multilingual Matters.

https://doi.org/10.21832/9781853597190

Muñoz, C. (2006). The effects of age on foreign language learning: The BAF project. Age and the rate of foreign language learning, 19, 1-40. https://doi.org/10.21832/9781853598937-003

Muñoz, C. (2008). Age-related differences in foreign language learning. Revisiting the empirical evidence. International Review of Applied Linguistics in Language Teaching, 46(3), 197-220. https://doi.org/10.1515/IRAL.2008.009

Muñoz, C., \& Singleton, D. (2011). A critical review of age-related research on L2 ultimate attainment. Language teaching, 44(1), 1-35. https://doi.org/10.1017/S0261444810000327

Oller, J. W., \& Nagato, N. (1974). The long-term effect of FLES: An experiment. The Modern Language Journal, 58(1/2), 15-19. https://doi.org/10.2307/323984

Olson, L. L., \& Jay Samuels, S. (1973). The relationship between age and accuracy of foreign language pronunciation. The Journal of Educational 
Research, 66(6), 263-268.

https://doi.org/10.1080/00220671.1973.10884476

Oyama, S. (1976). A sensitive period for the acquisition of a nonnative phonological system. Journal of psycholinguistic research, 5(3), 261-283. https://doi.org/10.1007/BF01067377

Patkowski, M. S. (1980). The sensitive period for the acquisition of syntax in a second language. Language learning, 30(2), 449-468.

https://doi.org/10.1111/j.14671770.1980.tb00328.x

Pavlenko, A., \& J. P. Lantolf (2000). Second language learning as participation and the (re)construction of selves. In J. P. Lantolf (ed.), Sociocultural theory and second language learning. Oxford: Oxford University Press, 155-178.

Tragant, E., \& Victori, M. (2006). Chapter 9. Reported strategy use and age. In M. Carmen (Ed.), Age and the Rate of Foreign Language Learning (pp. 208-236). Multilingual Matters.

https://doi.org/doi:10.21832/9781853598937-011

Victori, M., \& Tragant, E. (2003). Learner strategies: A cross-sectional and longitudinal study of primary and high-school EFL learners. In Age and the acquisition of English as a foreign language (pp. 182-209). Multilingual Matters.

https://doi.org/10.21832/9781853596407-010

Webb, S. (2020). Incidental vocabulary learning. In S. Webb (Ed.), The Routledge Handbook of Vocabulary Studies (1st ed., pp. 225-239).

https://doi.org/10.4324/9780429291586 